\title{
Frames of reference in preschoolers' perception of motion
}

\author{
CHERYL A. CAMENZULI and CELIA B. FISHER \\ Fordham University, Bronx, New York
}

\begin{abstract}
Experiments 1 and 2 established children's (mean age 3 years, 7 months) subject-relative and object-relative motion thresholds at $1^{\circ} 31.37^{\prime} / \mathrm{sec}$ and $1^{\circ} 9.33^{\prime} / \mathrm{sec}$, respectively, speeds well above those found for adults. Experiment 3 established that preschoolers, like adults, attribute object-relative motion to the smaller of two objects, with the inducing properties of the larger stimulus greatest when it is surrounding rather than adjacent to a smaller stimulus. The inducing advantage of surroundedness was equivalent for a single-element square frame and a multielement six-dot frame.
\end{abstract}

Motion perception is a relative phenomenon involving change of location of an object with respect to a reference point. When there is only one object in the visual field, judgments of motion must depend upon egocentric, that is, subject-relative, cues. In most cases, however, objects do not move in homogeneous fields. Motion of an object occurs with respect to a number of other objects in the environment, and displacements are perceived relative to these objects. In fact, the addition of object-relative cues enables observers to detect motion at speeds well below the subject-relative threshold (Duncker, 1929/1967; Kinchla, 1971; Shaeffer \& Wallach, 1966). Although the presence of a stationary point in the field substantially lowers motion thresholds, without an unambiguous reference point, subjects cannot reliably determine which of the two points is in motion. In fact, the veridical motion of the moving dot can induce apparent motion in the stationary point, resulting in what Duncker called "induced motion" (Duncker, 1929/1967).

Which object serves as the inducing object has been found to depend on certain stimulus characteristics. First, regardless of which stimulus actually moves, the larger object tends to be perceived as a stationary referent imparting motion to the smaller object (Rock, 1975). Moreover, when a stationary

This research was conducted in partial fulfillment of the requirements for the PhD in Psychology at Fordham University by the first author under the supervision of the second author. Portions of the research were supported by NIMH Grant IR03MH37431-01 to $C$. Fisher. We thank the children and staff of the Jackson Heights Childrens Center, Inc., for their cooperation, and Kevin Camenzuli, Jonathan Galente, and Marjorie Melendez for invaluable help with apparatus construction and data collection. Portions of this article were reported at the Biennial Meeting of the Society for Research in Child Development, Detroit, April 1983. Requests for reprints should be sent to Cheryl Camenzuli, Department of Psychology, Brooklyn College of CUNY, Bedford Avenue and Avenue H, Brooklyn, NY 11210. point is surrounded by a moving square frame, it is the surrounded point, and not the surrounding object, which appears to move. This phenomenon, called the principle of surroundedness, was traditionally seen as the most elementary determinant of induced motion (Day, 1978; Wallach, 1959). Recent research, however, challenges this assumption. Researchers have suggested that it is not the fact that the frame surrounds the dot that leads to the generation of induced motion, but the fact that the closer together two objects are, the greater the effect one has on the other (Gogel, 1970). This new development has been called the principle of adjacency. In this context, surroundedness is simply an extreme form of adjacency; the surrounding frame being adjacent to the target object on all sides. A majority of the studies have demonstrated that a frame need only be adjacent to a stationary point to serve as an inducing agent (Gogel \& Newton, 1975; Gogel \& Teitz, 1976), although adjacency is not always sufficient (Brosgole, 1968; Gogel \& Koslow, 1972; Schulman, 1982).

Day, Miller, and Dickinson (1979) attempted to determine if surroundedness is a more effective principle than adjacency when stimulus characteristics, such as size, speed, and solidity of reference frame, were equated. Using a variety of frame patterns (a solid frame, a 2-dot frame, and a 6-dot frame), they found that an increase in the number of field elements brings about an increase in the frequency of motion reports for both surrounded and adjacent objects, with a decided advantage for surroundedness as a generator of induced motion only when frames are multielemental.

Adult judgments of object-relative displacement can be summarized as follows: Regardless of which stimulus actually moves, the larger object tends to be perceived as a stationary referent, imparting motion to the smaller object. The inducing effectiveness of a frame increases with the number of frame elements. These principles hold true whether the frame is ad- 
jacent to or surrounding the smaller stimulus. However, as the number of frame elements increases, surrounding frames appear to exert greater inducing power than adjacent frames. While research dealing with object-relative displacement and induced motion has looked at responses of adults under various stimulus conditions, object-relative motion perception $\mathrm{i}:$ : children has been virtually ignored. It was the intention of this research to study object-relative displacement and induced motion in preschool children, contrasting their performance with data obtained from adults.

\section{EXPERIMENT 1}

The aim of Experiment 1 was to establish subjectrelative thresholds in preschoolers and adults. To demonstrate the facilitating effect of a second object on motion perception, the investigation of objectrelative motion requires stimulus speeds below the minimal amount of motion necessary to perceive a single object as moving in a homogeneous visual field. As the subject-relative threshold of preschool children had not previously been tested, thresholds established in Experiment 1 were a prerequisite for determining the speed at which object-relative motion perception would be tested in later experiments.

It was determined that the most appropriate approach to subject-relative threshold measurement would be to hold duration constant and vary speed. This decision was based on two important factors. First, it was comparable in methodology to the only previous study of subject-relative motion in children. Carpenter and Carpenter (1958) presented two young subjects with a 2-sec trial in which line segments moved left or right at varying speeds. Their findings showed threshold to be at $1^{\circ} 42.34^{\prime} / \mathrm{sec}$ for a 6.75 -year-old and $0^{\circ} 26.76^{\prime} / \mathrm{sec}$ for an 8.42-year-old. Both of these thresholds are higher than those obtained for adults at similar durations, for example, $12.18^{\prime} / \mathrm{sec}$ at $1.91 \mathrm{sec}$ (Brown \& Conklin, 1954) and 13.24\% $/ \mathrm{sec}$ at $2 \mathrm{sec}$ (Mack, Fisher, \& Fendrich, 1975). Second, when testing young children, the decision to hold duration constant is preferable when the definition of the subject-relative threshold is seen as a prerequisite to determining speeds for testing object-relative motion. That is, the stipulation that object-relative speeds be below the subject-relative threshold requires shortening the duration considerably if duration is the aspect that is to be varied. This could result in durations well below $1 \mathrm{sec}$, a time interval we believed would heavily tax the preschooler's ability to selectively attend to and judge which of two small objects was moving.

Another important point to consider when testing subject-relative threshold is the accuracy criterion adopted by different researchers. Mack et al. (1975), for example, looked for $75 \%$ accuracy in motion reports before determining that threshold had been established. Shaeffer and Wallach (1966), in contrast, worked with the more traditionally accepted $50 \%$ accuracy (Gescheider, 1976), which leads to a less stringent (or lower) absolute threshold. In Experiment 1 , the $50 \%$ accuracy criterion was employed. Once again, the decision was based on the fact that the subject-relative threshold determined by Experiment 1 would be a reference point upon which to determine object-relative speeds. The very conservative $75 \%$ accuracy criterion (and consequently higher thresholds) increases the probability that speeds chosen for object-relative testing will be high enough to enable subjects to detect motion without the facilitating presence of a second object.

\section{Method}

Subjects. Six preschool children, four males and two females (mean age, 3 years 7 months; range, 2 years 6 months to 4 years 2 months), and six adults, two males and four females (mean age, 30 years; range, 20-50), were tested. Two adults were eliminated from the study because they wore glasses that did not fit into the eyepiece of the apparatus. They were replaced by two new subjects. Two children completed the first testing session but did not wish to continue testing and were replaced by two new subjects.

Stimulus and Apparatus. Since subject-relative motion is relative solely with respect to the self, stimuli for this experiment were presented in a light-tight box that eliminated all environmental cues. The box had a removable back panel to facilitate the changing of stimulus patterns. The variable-speed dial and direction switch fit into a slot in the side of the box so that they could be easily regulated by the experimenter. The box was $30 \mathrm{~cm}$ long, $32 \mathrm{~cm}$ wide, and $40 \mathrm{~cm}$ high, and was covered with heavy black felt to prevent light seepage. The motor itself was painted in flat black to prevent reflection of light from luminescent stimuli.

A circular hole, $11.5 \mathrm{~cm}$ in diameter and $12 \mathrm{~cm}$ from the left edge of the box, was used as the viewing window. A light-tight viewing tunnel (a tube painted in flat black) was attached to the window. The outer end of the viewing tube was fitted with a binocular eyepiece surrounded by a black velvet "pillow" that fitted up against the subject's face and prevented any light seepage from around the head of the subject. The tube was $11 \mathrm{~cm}$ in diameter; it was $45.72 \mathrm{~cm}$ long for adults and $22.5 \mathrm{~cm}$ long for children. Reducing the subject's viewing distance from the stimuli increases the retinal extent of motion, thus increasing the perceived speed. Therefore, shortening the viewing tube enabled the experimenter to present stimuli at higher speeds for child subjects.

The stimulus for Experiment 1 was a single red "grain of wheat" bulb. To compensate for differences in viewing distance, the absolute diameter of the light point was varied, using black paint, so that for both age groups the stimulus subtended a visual angle of $.80^{\circ}$. Since the amount of light given off by the "grain of wheat" bulbs was too small to be measured accurately, the bulbs used for all experiments were replaced after every four subjects. This was done to insure that they were equally luminous for all subjects over the course of the study. The "dot" for Experiment 1 was moved by a Lafayette Illusionator (Model 14015). A conveyor belt attached to the rotating shaft of the Illusionator moved the stimulus left and right. The bulb was connected to a Variac which regulated intensity of presentations (the Variac setting used for all subjects was 100). The Variac and the Illusionator were both attached to a $2-\mathrm{sec}$ timer so that the lights and motor went on and off at precisely the same time. Speed was defined as the visual angle of the distance traversed by the stimulus per second. The five estimated speeds were chosen on the basis of past experiments: Carpenter and Carpenter (1958) reported subject relative thresholds for a 6-year-old and an 8-year-old at $1^{\circ} 42.34^{\prime}$ and 
$0^{\circ} 26.76^{\prime} / \mathrm{sec}$, respectively, and Mack et al. (1975) established adult threshold at $13.21^{\prime} / \mathrm{sec}$. The speeds tested were $49.48^{\prime}$, $1^{\circ} 11.23^{\prime}, 1^{\circ} 18.35^{\prime}, 1^{\circ} 39.72^{\prime}$, and $2^{\circ} 8.21^{\prime} / \mathrm{sec}$ for children, and $5.9^{\prime}, 8.89^{\prime}, 11.85^{\prime}, 14.8^{\prime}$, and $20.7^{\prime} / \mathrm{sec}$ for adults.

Procedure. A forced-choice procedure was employed with both children and adults. The subjects were asked to indicate, by pointing in the direction of perceived motion, whether the dot had moved left or right. Pointing was chosen as the method of response for both age groups because 3-year-olds have difficulty in labeling left and right. The subjects received a total of 100 trials, 20 at each of five speeds, of which half moved to the left and half moved to the right. Adult testing was completed in 1 day. Because the procedure took a great deal of time, the children were tested over a period of 2 days at 50 trials per day.

As the task was a difficult one to attend to, it was made gamelike for the children. The children watched the experimenter place a stuffed Cookie Monster carrying a small red felt ball inside the viewing box. The children were told that the Cookie Monster was going to throw the ball to one of his friends, a stuffed lion and a stuffed teddy bear. One animal was placed on the outside right of the box; the other was placed on the left. These positions were alternated randomly across subjects. The children were asked to look through Cookie Monster's window (the viewing tube with a piece of decorated cardboard placed around it to make it look like a window) and to watch the ball that Cookie Monster threw (the red "grain of wheat" bulb). At the end of the 2-sec trial, the children were asked to take their heads away from the window and point to the stuffed animal that Cookie Monster had thrown the ball toward.

\section{Results}

The subject-relative motion thresholds of adult subjects were $6.65^{\prime}, 9.63^{\prime}, 11.85^{\prime}, 13.03^{\prime}, 14.80^{\prime}$, and $17.42^{\prime} / \mathrm{sec}$, averaging at $12.23^{\prime} / \mathrm{sec}$. This finding is comparable to previous reports of adult thresholds at similar (2-sec) durations (Brown \& Conklin, 1954; Mack et al., 1975). The subject-relative motion thresholds of child observers were $1^{\circ} 0.54^{\prime}, 1^{\circ} 18.35^{\prime}$, $1^{\circ} 31.17^{\prime}, 1^{\circ} 39.72^{\prime}, 1^{\circ} 39.72^{\prime}, 1^{\circ} 58.70^{\prime} / \mathrm{sec}$, averaging at $1^{\circ} 31.37^{\prime} / \mathrm{sec}$. Three-year-olds' subject-relative thresholds are therefore higher than those reported for school-age children, which in turn are higher than those found for adults.

\section{EXPERIMENT 2}

The major aim of this investigation was to examine the stimulus characteristics affecting the preschool child's judgment of object-relative motion. Before this question could be dealt with, however, a broader issue had to be addressed. Do young children perceive object-relative motion when stimulus movement is below the subject-relative threshold? Wallach (1976) has suggested that induced motion occurs as a result of learning. The young child initially judging motion with respect to the self (subject-relative judgments) learns that stimulus motion produces a configurational change between the object and other stimuli in the visual field. Recent work with infants would suggest that sensitivity to induced motion is acquired quite early in human development. Lasky and Gogel (1978) found that a change in object-relative motion cues significantly reduced the decline of fix- ation in 5-month-old infants. While no empirical evidence concerning the phenomenon of object-relative motion has been reported for children, their susceptibility to adjacent configurational cues has been demonstrated in other areas of perception, such as orientation tasks and visual-geometric illusions (Coren \& Girgus, 1978; Fisher, 1982; Witkin, 1959). Indeed, it has been argued that young children spontaneously code perceptual experiences relationally (Bryant, 1974).

The criterion for determining object-relative motion perception is that the observer must reliably judge the direction of displacement of stimuli moving below the subject-relative threshold. This necessitates choosing a testing speed that is below the subjectrelative threshold and above the object-relative threshold. The object-relative threshold is extremely low in adults, estimated at $1^{\prime}$ or $2^{\prime} / \mathrm{sec}$ (Aubert, 1886). The traditional procedure for choosing object-relative speeds for adult studies has been to present stimuli at approximately half the speed determined as the subject-relative threshold (Day et al., 1979). Following the establishment of preschool subject-relative thresholds in Experiment 1, preliminary tests with child subjects indicated that speeds $50 \%$ below their subject-relative thresholds did not produce reliable judgments of object-relative displacement. (The object-relative judgments of the five subjects tested yielded the following percentages of correct responses: $36 \%, 56 \%, 56 \%, 50 \%$, and $65 \%$.) This suggested that speeds $50 \%$ below the subject-relative threshold are also below the young child's threshold for perceiving object-relative motion. Therefore, Experiment 2 was conducted to determine the objectrelative thresholds for the preschool age group.

\section{Method}

Subjects. Six preschool children, four males and two females (mean age, 3 years 8 months; range, 3 years 5 months to 4 years 1 month), were tested.

Procedure. Experiment 2 employed the same methodology and apparatus as Experiment 1, with one exception. In this instance, there were two dots, vertically aligned, $3.18^{\circ}$ of visual angle between centers, in the visual field. Each dot subtended a visual angle of $.80^{\circ}$. For each trial, one dot moved and one remained stationary. The subjects were asked whether the "airplane" (the stimuli were described to the subjects as being the lights of two airplanes) on the top or the one on the bottom had flown away and to indicate direction of motion by pointing. A response was scored as correct if it was one of either veridical or induced motion. For example, if the top stimulus had moved to the left, responses of top moved to the left or bottom moved to the right were both scored as correct. The speeds tested were $49.48^{\prime}, 1^{\circ} 11.23^{\prime}$, $1^{\circ} 18.35^{\prime}, 1^{\circ} 39.72^{\prime}$, and $2^{\circ} 8.21^{\prime} / \mathrm{sec}$.

\section{Results}

The object-relative motion thresholds of the six children tested were: $49.86^{\prime}, 1^{\circ} 9.33^{\prime}, 1^{\circ} 11.23^{\prime}, 1^{\circ} 14.79^{\prime}$, $1^{\circ} 14.79^{\prime}$, and $1^{\circ} 15.98^{\prime} / \mathrm{sec}$, averaging at $1^{\circ} 9.33^{\prime} / \mathrm{sec}$. This speed is $25 \%$ below the subject-relative motion threshold established for preschoolers in Experiment 1. Experiment 2 thus demonstrated that the 
presence of a stationary object in the visual field lowers motion thresholds for young children.

\section{EXPERIMENT 3}

The aim of Experiment 3 was to examine the effect of different stimulus characteristics on preschoolers' judgments of object-relative motion and to contrast their performance with that of adults. Specifically, we were interested in the stimulus characteristics that determine which of two stimuli will be perceived as stationary, inducing the perception of motion in the second object. To this end, we sought to (1) establish whether the larger object in the visual field served as the inducing agent, (2) compare the inducing effectiveness of a surrounding versus an adjacent frame, and (3) compare the inducing effectiveness of three distinct frame types: a solid square, a 2-dot frame, and a 6-dot frame.

\section{Method}

Subjects. Thirty-six children, 19 males and 17 females (mean age, 3 years 5 months; range, 2 years 6 months to 4 years 3 months) and 36 adults, 15 males and 21 females (mean age, 22 years; range 18 to 40 years) were assigned randomly to one of three different experimental conditions with 12 children and 12 adults in each. Three children began the study but did not wish to continue and were replaced. Five adult subjects were replaced, three because their glass frames allowed light seepage at the eyepiece and two because the stimulus motion was above their subject-relative thresholds.

Stimuli and Apparatus. The apparatus was identical to that used in Experiment 1: The stimuli were viewed through an eyepiece on a black, light-tight "tunnel" attached to a display box. The stimuli consisted of a series of "grain of wheat" bulbs arranged in patterns adapted from Day et al. (1979), illustrated in Figure 1. Moving stimulus patterns were attached to a conveyor belt; stationary stimuli were presented by placing bulbs on thin, black wooden sticks attached to a block of wood on the side of the Illusionator. The solid frame was made by illuminating the sides of a piece of acrylic on which a square had been etched. As in Experiment 1 , it was necessary to shorten the viewing distance $23.22 \mathrm{~cm}$ for child subjects in order to present stimuli at increased speeds. Consequently, to equate visual angle of stimulus presentations, separate sets of stimulus patterns, varying in absolute size, were constructed for child and adult subjects. Experiment 3 was designed to test the effect of frame size, position (surrounding or adjacent), and composition (holistic or multielemental) on object-relative motion judgments. If subjects consistently attribute motion to

\section{Surroundediness}

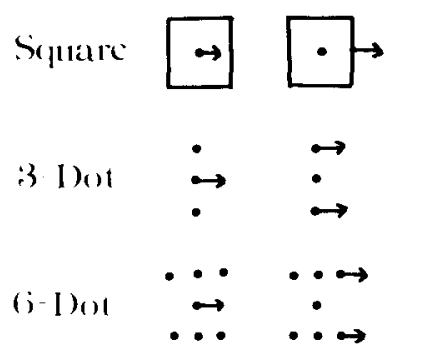

Figure 1. Stimulus patterns used in Experiment 3. Arrows indicate which element(s) of the display moved. the larger of two stimuli (the frame), then, whether the dot or the frame actually moves, the dot should be perceived as the moving object. It was for this reason that half of the stimulus presentations contained a moving dot and the other half contained a moving frame.

In Condition 1, surroundedness versus adjacency was examined using the most traditional stimuli-a single-element square $\left(3.18^{\circ}\right.$ of visual angle) and a dot $\left(.80^{\circ}\right.$ of visual angle). There were two stimulus arrangements. In the first, the dot was centered within (and thus surrounded by) the square frame. For half of the trials, the dot moved left or right (randomly determined), and for the other half, the frame moved left or right. In the second stimulus arrangement, the dot was $.98^{\circ}$ to the left of (and thus adjacent to) the frame. Again, half of the trials were of dot motion and half were of frame motion.

Condition 2 served to further identify the nature of an inducing frame by asking whether a pair of vertically aligned dots was more influential as a reference frame than a single, holistic element (the square frame of Condition 1). As in Condition 1, there were two stimulus arrangements. In the first (the surroundedness) arrangement, half of the trials consisted of a center dot that moved left or right, and in the remaining trials, the outer dots moved left or right. In the second (the adjacency) arrangement, for half the subjects, the lower two dots served as frame, and for the other half, the upper dots served as frame. As in Condition 1, half of the trials were of dot motion and half were of frame motion.

Condition 3 tested for the inducing effects of a stronger multielement frame on stimuli surrounded by or adjacent to this frame. The frame was composed of two horizontally aligned rows of three equidistant dots. The area enclosed by this six-element frame was identical to that of the square used in Condition $1-3.18^{\circ}$. In the surroundedness arrangement, a seventh dot was centered within the six-dot surround. In the adjacency arrangement, this dot was positioned $.98^{\circ}$ to the left of the multielement frame. As in the previous conditions, for both arrangements, the dot moved left or right for half of the trials and the frame moved left or right for half of the trials.

As noted in Experiment 2, to choose a speed at which objectrelative motion perception can be tested, one must be certain that the speed will be both below subject-relative threshold and above object-relative threshold. Age differences in the relationship between subject-relative and object-relative thresholds mandated that the speeds chosen for child and adult subjects could not be equated in terms of a constant percentage of their subject-relative thresholds. Since object-relative threshold is so low in adults (between $1^{\prime}$ and $2^{\prime} / \mathrm{sec}$, Aubert, 1886), object-relative speed has traditionally been placed at half the subject-relative threshold. This procedure resulted in an object-relative speed of $5.9^{\prime} / \mathrm{sec}$ for adult subjects in Experiment 3, a speed which closely approximated the 6.0 $/ \mathrm{sec}$ speed employed by Day et al. (1979). As demonstrated in Experiment 2, however, this method of choosing an objectrelative speed was not successful with child subjects; speeds $50 \%$ below subject-relative threshold are also below object-relative threshold. We therefore tested children at a speed of $1^{\circ} 11.23^{\prime} / \mathrm{sec}$, a speed that was $23 \%$ below the mean subject-relative threshold established in Experiment 1. Pilot testing had indicated that when the object-relative speed was raised to $23 \%$ of the mean subjectrelative threshold, adults were often able to make motion judgments based on subject-relative cues.

Procedure. For each condition, stimulus arrangements were presented for 16 trials each ( 8 of dot motion, 8 of frame motion), for a total of 32 trials. The order of presentation was determined randomly in advance for each subject. The requirement of correct object-relative displacement judgments necessitated the rerunning of trials on which subjects made errors. This was done at the end of a testing session. To insure that subjects were not responding from expectation, trials were not rerun immediately. Eight of the 36 child subjects made incorrect object-relative judgments (range, 1-3 errors in 32 trials) and 8 of the 36 adults made incorrect objectrelative judgments (each of these subjects made 2 errors in 32 trials). To ensure that subjects' responses were based on object- 
relative judgments, at the beginning of the session each subject was given 20 presentations of a single dot at the object-relative speed and asked to judge the direction of motion. All but two adult subjects performed at chance levels, demonstrating that the speed chosen was below the subject-relative threshold. The two subjects who responded above chance were replaced with two new subjects who performed at chance levels.

The adult subject's task in each condition was to report whether the dot or the frame in the display had moved, and to point in which direction. At the beginning of each trial, the experimenter signaled "ready" to prepare the subject for the 2-sec trial. The subject's response was recorded by the experimenter while an assistant changed the stimulus pattern for the next trial. The intertrial interval was approximately $20 \mathrm{sec}$. The procedure was forced choice: The subject had to choose either the dot or the frame as having moved on each trial.

Instructions for child subjects necessitated their conceptualizing elements belonging to the 2-dot and 6-dot frames as members of a unit, without relying on an understanding of the term "frame." For this reason, children were told that the elements of the frames were the lights of a large airplane (as opposed to the single dot light of the small airplane) and that they would always move together. The child subjects were told that they were going to look through Cookie Monster's window where they would see the lights from a small airplane and from a large airplane. They were asked to watch carefully and then to tell Cookie Monster whether it was the large or the small plane that had flown and to point in the direction that it had flown. Preliminary testing indicated that children's reports of frame and dot motion (and their respective directions) were random unless they were asked to focus on a particular aspect of the display. Therefore, they were instructed to "watch" the big airplane (the frame) for 16 trials and then the small airplane (the dot) for 16 trials. Which aspect of the display was "watched" first was alternated randomly across both child and adult subjects. Thus, stimulus presentations were randomized in such a way that, for all subjects, of each set of 16 trials half contained surroundedness and half adjacency, half contained dot motion and half frame motion, and half contained left stimulus trials and half right stimulus trials. As will be discussed in the results section, instructions to focus on one aspect of the display did not inhibit motion reports of the "unwatched" stimulus.

\section{Results}

The mean frequencies of perceived dot movement for three frame conditions and two age groups are shown, with their standard deviations, in Tables 1 and 2. Table 1 presents the data in terms of responses under dot-moving and frame-moving presentations. Table 2 collapses across this factor (which failed to
Table 2

Mean Number of Child and Adult Reports of Perceived Dot Motion by Age, Frame Condition, and Stimulus Arrangement

\begin{tabular}{llllll}
\hline \multirow{4}{*}{ Subjects } & & \multicolumn{3}{c}{ Stimulus Arrangement } \\
\cline { 3 - 4 } Children & Frame & \multicolumn{2}{c}{ Surroundness } & & \multicolumn{2}{c}{ Adjacency } \\
\cline { 3 - 4 } Adults & Square & $6.50^{*}$ & 1.74 & 6.12 & 1.56 \\
& Two-dot & 6.90 & 1.38 & 5.90 & 1.50 \\
& Six-dot & 6.33 & 1.61 & 5.50 & 2.08 \\
& Square & 7.00 & 1.50 & 6.67 & 1.57 \\
& Two-dot & 5.67 & 1.50 & 4.12 & 2.34 \\
& Six-dot & 6.87 & 1.70 & 6.37 & 1.92 \\
\hline
\end{tabular}

Note-Twelve children and 12 adults/condition were tested. Data illustrated is collapsed across dot/frame moving conditions.

*Maximum possible trials $=8$.

reach significance in the ANOVA) to more clearly illustrate response patterns by age, frame condition, and stimulus arrangement.

The data indicate that the addition of objects to the visual field moving at speeds below subject-relative threshold leads to the perception of object-relative motion in children as well as adults. Direction of displacement between the dot and the frame was correctly detected (either veridically or as induced motion) $98.4 \%$ of the time for child subjects and $98.6 \%$ of the time for adult subjects. The results of a fourway ANOVA with age and frame condition as betweensubject factors and stimulus arrangement (surroundedness vs. adjacency) and dot versus frame motion as within-subject factors yielded significant main effects for surroundedness versus adjacency $[F(1,66)=16.59$, $p<.001]$ and for frame condition $[F(2,66)=4.11$, $\mathrm{p}<.05]$, as well as a significant age $\times$ frame condition interaction $[F(2,66)=7.21, p<.01]$. No other effect, including the main effect for age, proved significant.

Work with adults suggests that the large object in the visual field serves as the inducing object (Rock, 1975; Schulman, 1982). The number of times the dot was reported as moving by all subjects is reported

Table 1

Mean Number of Child and Adult Reports of Perceived Dot Motion under Dot-Moving (DM) and Frame-Moving (FM) Conditions

\begin{tabular}{|c|c|c|c|c|c|c|c|c|c|}
\hline \multirow[b]{4}{*}{ Subjects } & \multirow[b]{4}{*}{ Frame Condition } & \multicolumn{8}{|c|}{ Stimulus Arrangement } \\
\hline & & \multicolumn{4}{|c|}{ Surroundedness } & \multicolumn{4}{|c|}{ Adjacency } \\
\hline & & \multicolumn{2}{|c|}{$\mathrm{DM}$} & \multicolumn{2}{|c|}{ FM } & \multicolumn{2}{|c|}{ DM } & \multicolumn{2}{|c|}{$\mathrm{FM}$} \\
\hline & & Mean & SD & Mean & SD & Mean & $\mathrm{SD}$ & Mean & $\mathrm{SD}$ \\
\hline Children & $\begin{array}{l}\text { Square } \\
\text { Two-dot } \\
\text { Six-dot }\end{array}$ & $\begin{array}{l}6.50 * \\
7.00 \\
6.00\end{array}$ & $\begin{array}{l}2.02 \\
1.41 \\
1.65\end{array}$ & $\begin{array}{l}6.50 \\
6.83 \\
6.67\end{array}$ & $\begin{array}{l}1.50 \\
1.40 \\
1.55\end{array}$ & $\begin{array}{l}6.40 \\
5.90 \\
5.16\end{array}$ & $\begin{array}{l}1.31 \\
1.61 \\
2.24\end{array}$ & $\begin{array}{l}5.80 \\
5.90 \\
5.83\end{array}$ & $\begin{array}{l}1.80 \\
1.44 \\
1.94\end{array}$ \\
\hline Adult & $\begin{array}{l}\text { Square } \\
\text { Two-dot } \\
\text { Six-dot }\end{array}$ & $\begin{array}{l}7.00 \\
6.16 \\
7.00\end{array}$ & $\begin{array}{l}1.59 \\
1.52 \\
0.99\end{array}$ & $\begin{array}{l}7.00 \\
5.16 \\
6.67\end{array}$ & $\begin{array}{l}1.47 \\
1.46 \\
2.22\end{array}$ & $\begin{array}{l}7.00 \\
4.91 \\
6.25\end{array}$ & $\begin{array}{l}1.24 \\
2.35 \\
2.01\end{array}$ & $\begin{array}{l}6.25 \\
3.33 \\
6.50\end{array}$ & $\begin{array}{l}1.81 \\
2.14 \\
1.93\end{array}$ \\
\hline
\end{tabular}

Note-Twelve children and 12 adults were tested under each frame condition.

*Maximum number of trials $=8$. 
in Table 1. The data clearly show that the dot was chosen as the moving object more than $50 \%$ of the time for each frame condition (collapsed across age, $6.58,5.65$, and 6.27 for square, 2-dot, and 6-dot frames, respectively, all out of a maximum possible 8 ) and, overall, more than $75 \%$ of the time for children and adults (6.21 and 6.12, respectively, out of a maximum possible 8). In fact, reports of a dot motion did not differ significantly between frame-moving and dot-moving displays (the main effect for this factor did not yield significance in the ANOVA). Moreover, failure to find a significant age $\times$ dot moving/frame moving interaction supports the results of the ANOVA in suggesting that the inducing effect of the frame is similar for preschoolers and adults.

The main effect for stimulus arrangement was significant and did not interact with any other factor. Both children and adults showed an advantage for surroundedness over adjacency across all three frame conditions (6.58 vs. 5.84 and 6.51 vs. 5.72 , respectively). Combining child and adult data, when the frame surrounded the dot, dot motion was reported in an average of 6.55 of 8 trials, whereas an adjacent frame resulted in only 5.78 reports in 8 trials.

The main effect for frame condition yielded significance and interacted significantly with age. Post hoc tests contrasting responses to frame condition within each age group yielded significance for only one contrast: Adult induced-motion responses were significantly reduced when viewed in a 2-dot adjacent frame condition as opposed to either a solid adjacent frame or a 6-dot adjacent frame $[\mathrm{F}(1,132)=12.10, \mathrm{p}<.05]$. Thus, it appears as if differences in the characteristics of the frame were salient to adult performance but not to children's performance. Children's mean reports of dot motion to the solid, 2-dot, and 6-dot frames were $6.31,6.40$, and 5.91, respectively.

The responses of our adult subjects differ from those reported by Day and his colleagues in two ways: First, Day et al. found an advantage for surroundedness only when the frame was composed of multielements, with this advantage maximized for the 6dot frame, while we found the inducing advantage of surrounding over adjacent frames to hold over all three frame compositions. Second, Day et al. found the multielement frames to be the most effective inducing agents, while our study yielded results suggesting that adults perceive equivalent degrees of induced and veridical dot motion in the single-element square frame and the 6-dot frame, with poorer performance in the 2-dot frame condition. An explanation for the differences found in subjects' performance in these experiments may lie in differences in stimulus size. The necessity of building a portable apparatus to test children in their nursery schools necessitated presenting stimulus frames that subtended a larger visual angle than those presented by Day et al. $\left(3.18^{\circ}\right.$ as compared with Day's $\left..3^{\circ}\right)$. The increased size of our stimuli may have made the square more salient and thus a more effective inducer.

One explanation for the drop in number of reports of dot motion in the 2-dot frame condition may lie in the fact that this stimulus display was not really comparable to displays of the solid square and 6-dot frame. Because the dot is positioned on the side of the frame for adjacency patterns in the latter conditions, the dot is moving toward the frame when it is going to the right and away from it when it is going to the left. In the 2-dot condition, however, the dots are vertically aligned and thus the dot is always moving away from the frame, whether it is going left or right. For this reason, a follow-up study was conducted in which 12 adults and 12 children were tested, using a 3-dot stimulus pattern that was comparable to the solid square and 6-dot conditions for surroundedness and adjacency patterns. Rather than vertically aligning the three dots for the adjacency condition, the dots were arranged so that the two that composed the frame were vertically aligned, while the center dot was displaced $.98^{\circ}$ to the left of the 2-dot frame. In this way, the 2-dot adjacency condition was made equivalent to the square and 6-dot adjacency conditions in that motion to the left was away from the frame and motion to the right was toward the frame. Results with adults indicated that perceived dot motion did improve somewhat across all four stimuli. The mean perceived dot motion for the surroundedness condition was 6.26 (dot moving = 6.83; frame moving $=5.70$ ) and for the adjacency condition was 5.15 (dot moving $=5.50$; frame moving $=4.80$ ). While means were slightly higher across the four stimulus patterns in this new configuration, the pattern of responding remained the same, with the adjacency-frame moving pattern receiving the lowest number of perceived dot motion reports of all stimulus patterns in all conditions. Results with children were virtually identical to those obtained originally. Mean perceived dot motion for surroundedness was 6.79 (dot moving $=6.75$; frame moving $=6.83$ ) and for adjacency was 5.95 (dot moving $=5.83$; frame moving $=6.08$ ). Thus, the change in stimulus pattern did increase reports of perceived dot motion for adults in the 2-dot condition, but not to the level of responding of the other two frame conditions and does not appear to explain adult performance fully.

\section{GENERAL DISCUSSION}

The aim of this study was to determine the contextual conditions under which preschool children perceive motion of an object and to compare their perceptual judgments with those of adults. Experiment 1 demonstrated that 3-year-olds can use visually based subject-relative cues to determine motion of an object displayed in a homogeneous field. These ego- 
centrically based spatial judgments were made independently of a perceptual-motor response and are thus purely visual-perceptual in nature. In this regard, processes responsible for subject-relative motion perception in young children may be analogous to those proposed for adults: Motion displacements may be sensed directly by the image-retina system or indirectly from perceived changes in spatial location (Gregory, 1973).

The $1^{\circ} 31.37 / \mathrm{sec}$ average subject-relative threshold found for preschool subjects exceeds those reported for school-age children and adults. One explanation for the 3-year-old's relatively high motion threshold may be tied to age differences in latency to saccade to a stimulus. Consistent with past investigations (Carpenter \& Carpenter, 1958; Day, 1978; Day et al., 1979), the present study did not employ a fixation point at the onset of each test trial. Indeed, it is not clear whether the presence of a fixation point before the onset of stimulus motion affects threshold values (e.g., Johnson \& Scobey, 1982). In a pilot study in which a fixation point was used, followed by a tone to signal start of the trial, a strong autokinetic effect was observed. That is, subjects would report perceived motion in one direction before the actual onset of stimulus motion and in another direction after the onset. This resulted in confusion on the part of the subjects and a high degree of chance-level responding. However, although removing the fixation point eliminates the autokinetic problem, it may create another problem for child subjects. A recent study by Lane and Pearson (1983) demonstrates that although children can attend selectively to a prespecified spatial location in the absence of a fixation point, their response times lag behind those of adults (mean response latencies $=924$ vs. $473 \mathrm{msec}$, respectively). An increased latency would cause the eye to reach the onset point after actual motion had taken place, (1) causing the dot to be displaced off the fovea, and (2) requiring a remedial saccade. The retinal motion created by the remedial saccade could, in turn, interfere with processing of the actual dot displacement. Recall that higher thresholds are based upon increased distances traversed by the dot within a constant 2 sec period. As a result, children may not perceive motion until displacements are long enough to compensate for the two-step saccadic process.

Experiment 2 established that object-relative thresholds in children are lower than their thresholds for subject-relative motion. Although object-relative cues increase sensitivity to motion displacement in 3-year-olds, they do not do so to the extent exhibited by adults. Adults are able to perceive object-relative motion at speeds well below $50 \%$ of their subjectrelative threshold. In contrast, the mean object-relative motion threshold for preschoolers was only $25 \%$ below speeds required for subject-relative judgments. The higher velocities required by children for object- relative judgments can be explained by the age differences in latency to saccade discussed for higher subject-relative responses. It is also possible that the child subjects had difficulty with the object-relative task at slower speeds because of the complexity of the task they were asked to undertake. Adult and child subjects were required to make a three-part decision in responding to the task: (1) Did motion occur? (2) Which object moved? (3) In which direction did the moving object go? It is possible that the children's attention to the sequencing of task requirements may have interfered with visual short-term memory processes.

Experiment 3 established that children, like adults, attribute object-relative motion to the smaller of two objects, perceiving the larger object as stationary regardless of which stimulus is actually moving. Moreover, children respond similarly to adults in that perception of apparent motion in a smaller stationary object occurs when it is either adjacent to or surrounded by a moving frame. For both age groups, the inducing properties of a large frame are greatest when it is surrounding, rather than adjacent to, a smaller stimulus. There is an inherent problem in the comparison of surroundedness versus adjacency when square or 6-dot frames are employed; more frame elements are, in fact, adjacent to the target dot when it is surrounded by rather than adjacent to these frames. The special influence of surrounding frames is thus particularly underlined by the inducing advantage of surroundedness, as found in the 2-dot supplementary experiment. In that experiment, both adjacent and surrounding frameworks consisted of two dots equidistant from the target dot. We would conclude, however, that whether the effectiveness of surroundedness is due to its being taken as a better surrogate of the stationary environment or to theoretical and experimental difficulties in totally disembedding surrounding from adjacent cues remains an empirical question.

In conclusion, with one exception, 3-year-olds' judgments of object-relative motion are qualitatively similar to adults' judgments. While both age groups respond to adjacent and surrounding frames as stationary objects, the number of frame elements does not differentially affect children's reports of induced motion, but does affect adult reports: For adults, a 2-dot adjacent frame is a significantly poorer inducer than either an adjacent square or a 6-dot frame. One explanation for the effectiveness of frames as inducing agents is their approximation to the realworld environment, in which a single moving object displaces with respect to numerous objects in the visual field or with respect to the larger homogeneous horizon and ground plane. Adults' decreased responding to an adjacent 2-dot frame, therefore, may indicate that increased experience with object-relative displacements necessitates that a frame be more anal- 
ogous to these two instances to be an effective surrogate of the environment.

\section{REFERENCES}

Aubert, H. (1886). Die Bewegungsempfindung. Archiv für die Gesamte Physiologie des Menschen und der Tiere, 39, 347-370.

Brosgole, L. (1968). An analysis of induced motion. Acta Psychologica, 28, 1-44.

Brown, R. H., \& Conklin, J. E. (1954). The lower threshold of visible movement as a function of exposure time. American Journal of Psychology, 67, 104-110.

BRYANT, P. (1974). Perception and understanding in young children. New York: Basic Books.

Carpenter, B., \& Carpenter, J. T. (1958). The perception of movement by young chimpanzees and human children. Journal of Comparative and Physiological Psychology, 51, 782-784.

Coren, S., \& Girgus, J. S. (1978). Seeing is deceiving: The psychology of visual illusions. Hillsdale, NJ: Erlbaum.

DAY, R. H. (1978). Induced visual movement as nonveridical resolution of displacement ambiguity. Perception \& Psychophysics, 23, 205-209.

Day, R. H., Miller, J., \& Dickinson, R. G. (1979). Induced movement as nonveridical resolution of displacement ambiguity: Effect of enclosure and number of field elements. Perception \& Psychophysics, 25, 23-28.

Duncke R, K. (1967). Induced motion. In W. D. Ellis (Ed.), $A$ source book of Gestalt psychology (pp. 161-172). London: Routledge and Kegan Paul. (Duncker's original work published 1929)

Fisher, C. B. (1982). The role of stimulus alignment in children's memory for line orientation. Child Development, 53, 1070-1074.

Gescheider, G. S. (1976). Psychophysics method and theory. Hillsdale, NJ: Erlbaum.

GoGEL, W. C. (1970). The adjacency principle and three-dimensional, visual illusions. Psychonomic Monograph Supplements, 3, 153-169.

Gogel, W. C., \& Koslow, M. A. (1972). The adjacency principle and induced motion. Perception \& Psychophysics, 11, 309-314.
Gogel, W. C., \& Newton, R. E. (1975). Depth adjacency and the rod-and-frame illusion. Perception \& Psychophysics, 18, 163-171.

Gogel, W. C., \& Teitz, J. D. (1976). Adjacency and attention as determinants of perceived motion. Vision Research, 16, 839-845.

GREGORY, R. L. (1973). Eye and brain: The psychology of seeing. New York: McGraw-Hill.

Johnson, C. A., \& ScoBey, R. P. (1982). Effects of reference lines on displacement thresholds of various durations of movement. Vision Research, 22, 819-821.

Kinchla, R. A. (1971). Visual movement perception: A comparison of absolute and relative movement discrimination. Perception \& Psychophysics, 9, 165-171.

Lane, D. M., \& Pearson, D. A. (1983). Attending to spatial locations: A developmental study. Child Development, 54, 98-104.

LASKY, R. E., \& GoGEL, W. C. (1978). The perception of relative motion by young infants. Perception, 7, 617-623.

Mack, A., Fisher, C. B., \& Fendrich, R. A. (1975). A reexamination of two-point induced movement. Perception \& Psychophysics, 17, 273-276.

Rock, I. (1975). An introduction to perception. New York: Macmillan.

Schulman, P. H. (1981). Antagonistic effects of adjacency and apparent speed in induced motion. Journal of Experimental Psychology, 7, 985-994.

Shaeffer, O., \& Wallach, H. (1966). Extent of motion thresholds under subject-relative and object-relative conditions. Perception \& Psychophysics, 1, 447-451.

Wallach, H. (1959). Perception of motion. Scientific American, 201, 56-60.

WALLACH, H. (1976). On perception. New York: Quadrangle/ New York Times.

Witkin, H. A. (1959). The perception of the upright. Scientific American, 200, 51-56.

(Manuscript received October 24, 1983; revision accepted for publication May 18, 1984.) 